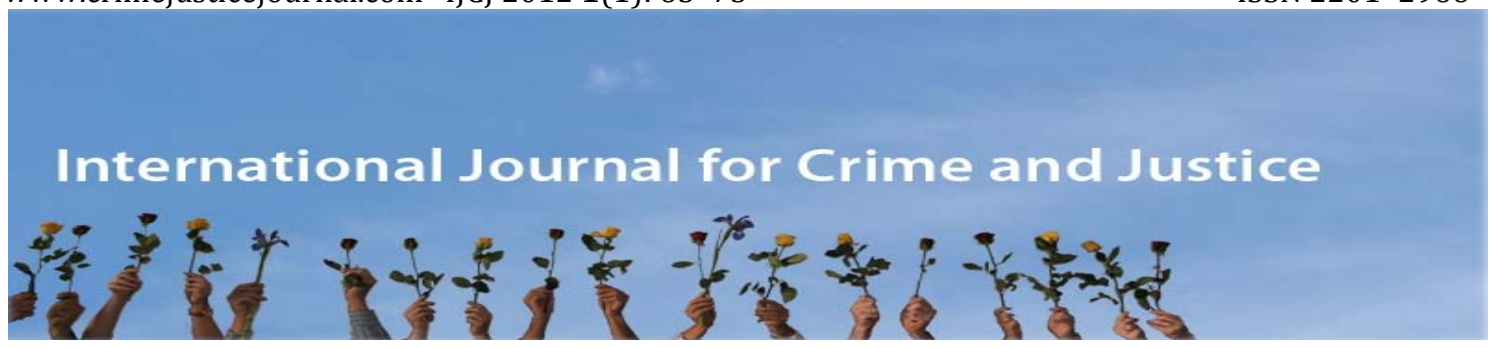

\title{
Human Rights and Environmental Wrongs: Achieving Environmental Justice through Human Rights Law
}

\author{
Bridget Lewis \\ Queensland University of Technology, Brisbane
}

\begin{abstract}
The numerous interconnections between the environment and human rights are well established internationally. It is understood that environmental issues such as pollution, deforestation or the misuse of resources can impact on individuals' and communities' enjoyment of fundamental rights, including the right to health, the right to an adequate standard of living, the right to self-determination and the right to life itself. These are rights which are guaranteed under international human rights law and in relation to which governments bear certain responsibilities. Further, environmental issues can also impact on governments' capacity to protect and fulfil the rights of their citizens. In this way human rights and environmental protection can be constructed as being mutually supportive.

In addition to these links between the environment and human rights, human rights principles arguably offer a framework for identifying and addressing environmental injustice. The justice implications of environmental problems are well documented and there are many examples where pollution, deforestation or other degradation disproportionately impact upon poorer neighbourhoods or areas populated by minority groups. On the international level, environmental injustice exists between developed and developing States, as well as between present and future generations who will inherit the environmental problems we are creating today. This paper investigates the role of human rights principles, laws and mechanisms in addressing these instances of environmental injustice and argues that the framework of human rights norms provides an approach to environmental governance which can help to minimise injustice and promote the interests of those groups which are most adversely affected. Further, it suggests that the human rights enforcement mechanisms which exist at international law could be utilised to lend weight to claims for more equitable environmental policies.
\end{abstract}

\section{Keywords}

Human rights, environmental justice, environmental equity, inter-generational equity, international law.

\section{Introduction}

Environmental justice is concerned with the fair and equal distribution of environmental burdens and benefits at local, national and international levels. It also strives to secure the 
meaningful participation in decision-making processes of those who are most likely to be affected by environmental changes which implicate them and to ensure that those who are negatively affected have adequate recourse to compensation or other remedies. Environmental injustice can therefore be identified wherever there is inequality or unfairness in the distribution of environmental burdens, where there is exclusion from the processes which determine how that distribution will be effected, or where disproportionate distribution is not balanced by sufficient reparation. This extends to potential injustices between developed and developing States, and between present and future generations.

It is not a coincidence that instances of environmental injustice are often accompanied by or constitute human rights violations. It has long been recognised that environmental harm can amount to a violation of human rights when it affects an individual's or a community's ability to enjoy or exercise their fundamental rights, such as the rights to health, to an adequate standard of living, or to self-determination. Where environmental harm is widespread, it is common to find violations of other rights including rights related to the freedom of the press, access to justice and participation in democratic processes of government. This paper explores the nature of the relationship between human rights and the environment, and in particular analyses the role which human rights principles, laws and mechanisms may play in identifying and addressing instances of environmental injustice. It argues that the framework of human rights law provides a normative approach to environmental governance which can help minimise injustice and promote the interests of those groups which are most adversely affected by environmental change. Further, it suggests that the human rights enforcement mechanisms which exist at international law could be utilised to lend more weight to claims for more equitable environmental policies.

\section{The relationship between the environment and the human rights legal framework}

International human rights law has come to recognise the vital role that the environment plays in ensuring that every individual is able to enjoy the rights which that body of law seeks to protect. In his separate opinion in the Gabcikovo-Nagymaros case before the International Court of Justice, Judge Weeramantry (1991: 207) stated that:

the protection of the environment ... is a vital part of contemporary human rights doctrine, for it is sine qua non for numerous human rights such as the right to health and the right to life itself. It is scarcely necessary to elaborate on this, as damage to the environment can impair and undermine all the human rights spoken of in the Universal Declaration on Human Rights and in other human rights instruments.

It is therefore a well accepted principle of human rights law that a healthy environment is a necessary precondition for the promotion and enjoyment of several recognised rights (Sachs 2003: 26). The environmental dimensions of existing human rights can be described as either direct or indirect: direct in the sense that a poor environment will directly limit an individual's or a community's ability to enjoy a specific right that is guaranteed to them; or indirect in the sense that a poor environment will affect an individual's or a community's capacity to realise their human rights generally, or impede a government's ability to protect and fulfil the rights of its citizens. In this sense environmental protection can be constructed as a prerequisite for the full enjoyment of human rights. The corollary of this approach is that environmental degradation can amount to a violation of human rights under international law. This section will outline some of the rights which are guaranteed under international human rights law and highlight the necessary role that the environment plays in ensuring these rights are fulfilled and protected. A subsequent section of this paper will consider in more detail the practical possibilities for using human rights enforcement mechanisms to promote environmental justice. 


\section{The right to health}

Article 12 of the International Covenant on Economic, Social and Cultural Rights (ICESCR) (1966) guarantees to all people the right to the highest attainable standard of health. This right is also articulated in the Convention on the Rights of the Child (1989), the Convention on the Elimination of All Forms of Discrimination Against Women (1979) and the International Convention on the Elimination of All Forms of Racial Discrimination (1965), as the right applies to those groups in particular.

In its General Comment 14 on the right to health, the United Nations Committee on Economic, Social and Cultural Rights elaborates on the scope and content of Article 12 of the ICESCR. It makes clear that the wording of the right to health in Article 12 is intended to include a wide range of socio-economic factors and underlying determinants of health, including 'food and nutrition, housing, access to safe and potable water and adequate sanitation, safe and healthy working conditions, and a healthy environment' as well as 'the prevention and reduction of the population's exposure to harmful substances such as radiation and harmful chemicals or other detrimental environmental conditions that directly or indirectly impact upon human health' (2000). General Comment 14 clearly indicates that the environment is considered a significant contributing factor to achieving an adequate standard of health and environmental problems such as pollution are constructed as barriers to full enjoyment of the right.

Article 24 of the Convention on the Rights of the Child similarly guarantees to every child the right to the highest attainable standard of health. That article specifically imposes an obligation on governments to provide 'adequate nutritious foods and clean drinking-water, taking into consideration the dangers and risks of environmental pollution'. The links between environmental quality and the right to health are therefore articulated in human rights law and the importance of the environment as a determinant of health is well understood.

\section{The right to an adequate standard of living}

Article 11 of the ICESCR guarantees to all individuals the right to an adequate standard of living, including adequate food, clothing and housing, and the continuous improvement of living standards. This right is also guaranteed to children under article 27 of the Convention on the Rights of the Child. The right to an adequate standard of living is considered to imply the right to water (Committee on Economic, Social and Cultural Rights 2002) as well as the right to food (Committee on Economic, Social and Cultural Rights 1999). Where environmental degradation such as pollution, deforestation or desertification affects the availability of clean and secure water supplies or limits a community's ability to provide adequate food and nourishment, then the right to an adequate standard of living is violated.

\section{Indigenous rights}

A number of human rights are specifically accorded to indigenous peoples under international law and these can also be adversely affected by environmental harm, especially where the environment plays a particular role in their traditional, cultural or spiritual lives. Article 27 of the International Covenant on Civil and Political Rights (ICCPR) (1966) states:

In those States in which ethnic, religious or linguistic minorities exist, persons belonging to such minorities shall not be denied the right, in community with the other members of their group, to enjoy their own culture, to profess and practise their own religion, or to use their own language.

Where the environment contributes to indigenous peoples' culture, spirituality or language, article 27 is potentially violated by acts which damage that environment. 
The International Labour Organisation's Convention 169 Concerning Indigenous and Tribal Peoples in Independent Countries includes measures to protect the environment of indigenous territories as well as traditional activities such as hunting, fishing, trapping and gathering (1989). Clearly these rights would also be threatened by environmental harm which affects indigenous lands and resources.

Indigenous peoples are also entitled to self-determination under common article 1 of the ICCPR and the ICESCR. Under the terms of that provision, all peoples have the right to dispose of their natural resources and must be protected against deprivation of their means of subsistence. Where environmental degradation is inflicted upon indigenous communities then the components of self-determination are threatened. A people's ability to guarantee their means of subsistence - be it through agriculture, fishing, hunting or gathering - is at risk where ecosystems or species which have been traditional sources of food are undermined. The ability of a people to utilise their natural resources may also be threatened where those resources are exploited, and especially where relevant decision-making processes exclude indigenous groups or where free, prior and informed consent is not obtained.

The importance of the environment to indigenous peoples is reinforced in the United Nations Declaration on the Rights of Indigenous Peoples (UNDRIP) (2007) which states in article 29 that:

Indigenous peoples have the right to the conservation and protection of the environment and the productive capacity of their lands or territories and resources. States shall establish and implement assistance programmes for indigenous peoples for such conservation and protection, without discrimination.

In addition to the specific rights outlined above, indigenous peoples are equally entitled to the full complement of human rights guaranteed under human rights law, without discrimination or distinction. The close relationship which many indigenous peoples have with their natural environment can create particular vulnerabilities in respect of these rights, however, and may require governments to take specific action in relation to indigenous communities which might not be required in relation to the broader population. For example, the cultural integrity and the mental and physical wellbeing of an indigenous group may be intimately linked to the health of their land and sea territories, such that interference with or degradation of those areas impacts upon the right to health and to an adequate standard of living (Green 2006). In these ways the environment can be seen as a fundamental factor in ensuring that indigenous peoples enjoy the full range of the rights which are guaranteed to them under international law.

\section{Capacity building relationship of human rights and the environment}

Environmental harm, be it in the form of pollution, deforestation, exploitation of natural resources or climate change, has the potential to impact on a wide range of human rights, as outlined above, and in some circumstances has been held to amount to a violation of human rights guaranteed by law. As well as the direct impact which the environment can have on specific rights, it is also recognised that the environment is a significant factor in contributing to a state's ability to protect and fulfil its citizens' human rights more broadly. At the same time, widespread enjoyment of human rights can be instrumental to achieving stronger protections for the environment as well. This mutually supportive relationship can be observed in a number of ways. First, if a state is dealing with serious environmental degradation problems caused by, for example drought, erosion, climate change or crop failures, it will often struggle to provide adequate protections for human rights. Competition for scarce governmental resources may lead to a prioritisation which directs funds away from economic, social and cultural rights (such as education or health) and a state may even feel it necessary to curtail some civil and political rights in order to address the environmental situation it is confronting. Not only will the environmental degradation create direct human rights impacts but it may also have indirect 
effects on a wide range of human rights which receive less support or attention as a result. By the same token, States which enjoy a relatively healthy environment which is capable of adequately sustaining their population will be better placed to devote more attention to other human rights issues.

On the other side of the account, where a State has strong human rights protections in place, it is often the case that environmental protection mechanisms are similarly more robust. A State with good protections of civil and political rights, including strong democratic processes, good access to justice and a free and independent media, will often be more inclined and better able to address environmental issues and work against exploitation of natural resources. This is not to say that environmental problems do not exist in States with strong human rights records, but there does seem to be a mutually reinforcing relationship between environmental protection and human rights such that capacity building in one area may have positive outcomes in the other.

On the basis of this multifaceted and mutually supportive relationship between human rights and the environment, arguably human rights principles can be used as a normative framework to assist with decision-making and policy formulation and that doing so can help achieve just outcomes. The following section considers the nature of environmental justice in order to demonstrate the sorts of problems which a human rights approach can help address.

\section{The concept of environmental justice}

The term 'environmental justice' which can be defined using a range of theoretical approaches encompasses a wide range of justice considerations. One formulation of environmental justice can be drawn from the emerging fields of eco-crime and green criminology, which provide an understanding of environmental justice based on conventional criminological discourses as they apply to environmental harm (see Walters 2010; White 2008). Another account of environmental justice is based on the theory of distributive justice whereby just outcomes are assessed according to the equality and fairness with which environmental benefits and burdens are distributed between individuals, communities and States (Bosselman and Richardson 1999). This paper uses the distributive justice model and argues that, where environmental injustice is identified, it is often accompanied by, or constituted of, human rights violations.

In 2008 Edith Brown Weiss wrote what might be considered a rather farsighted paper on climate change and equity. She argued that climate change represented an issue for environmental justice in terms of its unequal effects for certain communities, countries or generations. She drew on John Rawls' theory of justice (1971) to identify the problem of achieving distributive justice between members of the same generation in relation to the effects of climate change. In doing so she highlighted one of the key injustices of climate change: that people in developing States are likely to be worse affected because of their vulnerability to environmental change and their lower capacity to adapt to it (2008: 618). Although this problem is particularly well-illustrated by the problem of climate change, the same kind of injustice can be found in relation to many forms of environmental degradation. It is often the case that environmental harm such as pollution or deforestation affects poorer communities more seriously, be it because of their reliance on the environment for subsistence and their consequent vulnerability to environmental harm, or their economic incapacity to cope with such harm successfully, or a combination of these factors. Climate change entails an additional facet of environmental injustice, in that many of the people who will suffer worst, and in all likelihood first, from the effects of climate change are among the least responsible for its causes.

Climate change also illustrates another level of environmental injustice: injustice between present and future generations. Because of the extensive time frame over which the results of global warming are played out, there is a disparity between past and current generations who 
have been responsible for greenhouse gas emissions, and future generations who will have to live with the consequences (Chandani 2007). Brown Weiss identifies inequities in terms of the quality of the natural environment which future generations would inherit, as well as their access to natural and cultural resources. Her theory of inter-generational equity incorporated three elements: conservation of options; conservation of quality; and conservation of access. In discussing the challenge of climate change, she argued that our strategies must address these three issues, and we must strive to leave the Earth in no worse condition than we received (2008: 623).

Environmental justice can therefore be interpreted as operating on two planes: intra- and intergenerational justice. These two layers of justice do not operate independently however. As Brown Weiss pointed out: 'in the present generation, one cannot expect people to fulfil obligations to future generations if they are not able to satisfy their basic needs' (2008: 216). She argued that a failure to address the needs of communities today would exacerbate the inequalities facing future generations. This presents one of the key ways in which human rights principles can help address environmental injustice: by working towards the protection and fulfilment of human rights for all people, and particularly for developing States, we can build capacity in these communities so they can more meaningfully engage with sustainable development practices and focus their attention on the environmental legacy that they will leave for future generations. The following section will expand upon this notion of how a rightsbased approach can help achieve environmental justice.

\section{A human rights approach to achieving environmental justice}

There is a range of ways in which a human rights approach to environmental problems can help achieve just outcomes. As outlined above, a human rights approach which works towards capacity-building in developing States can help establish the conditions necessary to encourage sustainable development and thereby improve the likelihood of inter-generational equity. Intergenerational equity is also bolstered by a rights-based approach because a broad understanding of human rights requires not only that we protect the rights of present generations but also that we ensure that our actions today will not jeopardise the chances of future generations of enjoying those same rights. The following section will expand upon the role of human rights in these respects.

In terms of intra-generational equity, human rights principles have a valuable role to play. The capacity-building which Brown Weiss identified as a precondition to inter-generational equity also has positive consequence for environmental justice among members of the same generation. This can occur in a number of ways. Environmental problems may arise where impoverished communities or developing States strive to achieve economic development by any means available. By working towards full enjoyment of rights such as the right to adequate living standards, the right to education and the right to the highest attainable standard of health, these communities and their governments are under less pressure to pursue economic development at the expense of the environment but are instead better able to take more environmentally compatible and sustainable measures. Capacity-building also helps reduce communities' vulnerability to environmental exploitation by external parties, governmental or corporate. Further, when environmental problems do occur, such as those caused by climate change, communities possess greater resilience and capacity to adapt. This helps to mediate against the inequitable impact which climate change would have on developing States or otherwise vulnerable communities.

As well as promoting capacity-building in otherwise vulnerable communities, human rights principles can provide a normative framework to assist in more just decision-making in environmental governance. Where projects are proposed which would cause environmental changes, a rights-based approach would assess the human as well as the environmental impacts 
of such activity. This would involve assessing projects' implications for a range of human rights, including the rights to health, to housing, to an adequate standard of living and to selfdetermination. In this way, human rights can help identify potential injustices by focussing attention on the people who are likely to be affected and on the full range of impacts they are likely to experience. A rights-based approach would require that affected communities are afforded the opportunity to participate in any decision-making processes which have the potential to impact upon them and that free, prior and informed consent is obtained before action is taken which would damage communities' environments. A rights-based approach also incorporates the concepts of non-discrimination and equity that are central to sustainable development and which can help to ensure just outcomes for individuals and communities likely to be affected by environmental change (Atapattu 2008: 36).

In a practical sense the international human rights legal framework also offers a mechanism for achieving environmentally just outcomes. Human rights laws impose obligations on States to take steps to respect, protect and fulfil human rights. While the exact standard of obligation may vary depending on the particular right concerned and according to a State's capabilities, at the very least, States must refrain from activities which violate human rights. Where States fail to meet their obligations, criticism from the international community is given weight by international law. As our understanding of the relationship between the environment and human rights expands, so too do the ways in which States' obligations under international human rights law can be seen to entail obligations to protect the environment. In this sense, States which allow the exploitation or destruction of the environment can be criticised not only for violating principles of environmental protection and conservation but also for failing to protect the human rights of their citizens. The normative influence of human rights can therefore be brought to bear on States to prompt them to better address environmental injustice.

More practically useful perhaps than the normative weight of human rights law may be the availability of human rights tribunals, courts and committees, which could be utilised by individuals and communities who allege their human rights have been violated (Posner 2007: 3). For example, an individual may bring a complaint to the Human Rights Committee where there is an alleged violation of a right contained in the ICCPR (First Optional Protocol to the ICCPR 1976: art 1). Regional enforcement mechanisms may also provide an avenue for redressing environmental injustice. Several cases have already been successful before regional human rights tribunals, establishing that environmental degradation such as pollution or deforestation can amount to a violation of human rights. For example, in Lopez-Ostra vs Spain (1994), the European Court of Human Rights held that pollution caused by a waste treatment facility located near the complainants' home violated their right to privacy and family life (guaranteed under article 8 of the European Convention on Human Rights (1950)) by limiting their ability to enjoy their home. This was found to be the case even though the court did not find a violation of the right to health in the circumstances. In the Awas Tingni case before the Inter-American Court of Human Rights (2001), the Mayagna Awas (Sumo) Tingni community of Nicaragua argued that the Nicaraguan government had failed to protect its property rights over traditional lands and natural resources, which were to be commercially developed. The Court upheld the claim and agreed that the Community's property rights under the American Convention of Human Rights (1969) had been violated by the State's failure to provide an adequate system of indigenous title and protection of indigenous lands. These judicial avenues provide one option for communities or individuals unjustly affected by environmental harm where such harm can be construed as a violation of human rights.

There are limitations to the ability of the human rights regime to address environmental injustices. Access to the regime relies on States being parties to the relevant instruments of international law and in many cases individuals are unable to avail themselves of international or regional mechanisms until they have exhausted local legal options (Optional Protocol 1976: 
art 2). As well as these procedural limitations, any claim alleging a violation of human rights will face the causative challenge of proving that a particular State's conduct (either directly or through its failure to properly regulate non-State actors) caused the breach of human rights. This is particularly a challenge for any claim relating to climate change, where the cumulative and transnational impact of greenhouse gas emissions and the complex scientific processes involved make it very difficult to hold a particular State responsible for a specific outcome (Stephens 2010). Nonetheless, there is normative force in the human rights regime and the possibility of claims against States where they have failed to meet their human rights obligations may provide an important incentive for addressing environmental injustice.

\section{Conclusion}

Environmental injustice takes many forms and can be identified in disproportionate impacts on poorer neighbourhoods, developing States and future generations. In many cases environmental injustice can be described in terms of the human rights violations it represents, drawing on our evolving understanding of the interconnectedness of human rights and the environment. Beyond this descriptive function, the human rights framework also has a role to play in redressing and preventing environmental injustice. The utility of human rights in achieving environmental justice can be seen in three key areas. First, a rights-based approach to environmental governance can highlight more fully the human impact of environmental degradation and provide a set of norms against which to evaluate potential environmental harm. Second, by ensuring that all individuals and communities enjoy the full complement of human rights, we can build capacity for communities, particularly those in developing States, to focus more clearly on sustainable development strategies and just environmental outcomes. Finally, human rights enforcement mechanisms provide a valuable avenue for individuals and communities to seek redress for environmental injustice inflicted upon them. Together with other forms of environmental governance, human rights law provides a complementary and useful tool in achieving environmental justice for present and future generations.

Correspondence: Bridget Lewis, Lecturer, Law School, Faculty of Law, Queensland University of Technology, Brisbane Qld 4000, Australia. Email: b.lewis@qut.edu.au

\section{References}

American Convention on Human Rights ("Pact of San Jose, Costa Rica"), opened for signature 22 November 1969 (entered into force 18 July 1978).

Atapattu S (2008-2009) Global climate change: Can human rights (and human beings) survive this onslaught? Colorado Journal of International Environmental Law and Policy 20(1): 35-67.

Bosselman K and Richardson B (1999) Environmental Justice and Market Mechanisms: Key Challenges for Environmental Law and Policy. The Hague: Kluwer Law International.

Brown Weiss E (2008) Climate change, intergenerational equity and international law. Vermont Journal of Environmental Law 9(3): 615-638.

Chandani A (2007) Distributive justice and sustainability as a viable foundation for the future climate regime. Carbon and Climate Law Review 2: 152-163.

Convention on the Rights of the Child, opened for signature 20 November 1989, 1577 UNTS 3 (entered into force 2 September 1990).

Convention on the Elimination of All Forms of Discrimination Against Women, opened for signature 18 December 1979, 1249 UNTS 13 (entered into force 3 September 1981).

Gabcikovo-Nagymaros Project (Hungary v Slovakia) Separate Opinion of Vice-President Weeramantry, 37 ILM 168.

Green, D (2006) How might climate change affect island culture in the Torres Strait? CSIRO Marine and Atmospheric Research Paper 011. 
International Convention on the Elimination of All Forms of Racial Discrimination, opened for signature 21 December 1965, 660 UNTS 195 (entered into force 4 January 1969).

International Covenant on Economic, Social and Cultural Rights, opened for signature 16 December 1966, 993 UNTS 3 (entered into force 3 January 1976).

International Covenant on Civil and Political Rights, opened for signature 16 December 1966, 999 UNTS 171 (entered into force 23 March, 1976).

International Labour Organisation, Convention Concerning Indigenous and Tribal Peoples in Independent Countries, opened for signature 17 June 1989, Conv 169 (1989) reprinted in 28 ILM 1382 (entered into force 5 September 1991).

Lopez Ostra v Spain (1995) Eur Ct H R 38.

Mayagna (Sumo) Awas Tingni Community v Nicaragua judgement of 31 August, 2001, Inter-Am Ct H R (Ser C) No 70.

Optional Protocol to the International Covenant on Civil and Political Rights, opened for signature 16 December 1966, 999 UNTS 171 (entered into force 23 March, 1976).

Posner E (2007) Climate change and international human rights litigation: A critical appraisal. Chicago Public Law and Legal Theory Working Paper 148.

Rawls J (1971) A Theory of Justice. Cambridge: Harvard University Press.

Sachs W (2003) Environment and Human Rights. Wuppertal Institute for Climate, Environment, and Energy, Paper No 137, September 2003.

Stephens P (2010) Applying human rights norms to climate change: The elusive remedy. Colorado Journal of International Environmental Law and Policy 21(1): 49-83.

United Nations Committee on Economic, Social and Cultural Rights (1999) General Comment 12: The Right to Adequate Food. UN Doc No E/C.12/1999/5.

United Nations Committee on Economic, Social and Cultural Rights (2000) General Comment 14: The Right to Health. UN Doc No E/C.12/2000/4.

United Nations Committee on Economic, Social and Cultural Rights (2002) General Comment 15: The Right to Water. UN Doc No E/C.12/2002/11.

United Nations Declaration on the Rights of Indigenous Peoples (2007) General Assembly Resolution 61/295 (adopted 13 September 2007).

Walters R (2010) Toxic atmospheres air pollution, trade and the politics of regulation. Critical Criminology 18(4): 307-323.

White R (2008) Crimes Against Nature: Environmental Criminology and Ecological Justice. Collumpton: Willan Publishing. 